\title{
Sulfur and Nitrogen Dioxide Exposure and the Incidence of Health Endpoints in Ahvaz, Iran
}

\author{
Sahar Geravandi ${ }^{1,2}$; Gholamreza Goudarzi $^{3,4}$; Mohammad Javad Mohammadi ${ }^{4,2, *} ;$ Sepideh \\ Sadat Taghavirad ${ }^{5}$; Shokrollah Salmanzadeh $^{6}$ \\ ${ }_{1}^{1}$ Department of Nursing, Tehran Medical Sciences Branch, Islamic Azad University, Tehran, IR Iran \\ 2 Department of Nursing, Razi Hospital, Ahvaz Jundishapur University of Medical Sciences, Ahvaz, IR Iran \\ ${ }^{3}$ Environmental Technologies Research Center, Ahvaz Jundishapur University of Medical Sciences, Ahvaz, IR Iran \\ ${ }^{4}$ Department of Environmental Health Engineering, School of Public Health, Ahvaz Jundishapur University of Medical Sciences, Ahvaz, IR Iran \\ 5 Department of Occupational Health, School of Public Health, Mehr Hospital, Ahvaz Jundishapur University of Medical Sciences, Ahvaz, IR Iran \\ 5 Department of Occupational Health, School of Public Health, Mehr Hospital, Ahvaz Jundishapur University of Med
6 Infectious and Tropical Diseases Research Center, Ahvaz Jundishapur University of Medical Sciences, Ahvaz, IR Iran \\ *Corresponding author: Mohammad Javad Mohammadi, Department of Environmental Health Engineering, School of Public Health, Ahvaz Jundishapur University of Medical \\ Sciences, Ahvaz, IR Iran. Tel: +98-9355439707, Fax: +986113361544, E-mail: javad_sam2000@yahoo.com; Mohamadi.m@ajums.ac.ir
}

Received: October 3, 2014; Revised: December 28, 2014; Accepted: January 7, 2015

\begin{abstract}
Background: Sulfur and nitrogen dioxide can have harmful effects on human health. This pollutant can penetrate into sensitive parts of the respiratory system and cause or worsen Chronic Obstructive Pulmonary Disease (COPD), emphysema, bronchitis, and other respiratory diseases leading to increased hospital admissions and premature death.

Objectives: The purpose this study was to evaluate the effects of sulfur and nitrogen dioxide exposures on the incidence of health endpoints in Ahvaz City during 2012.

Materials and Methods: We collected data from Ahvaz Department of Environment (ADoE). Sampling was done in 4 stations of Naderi, Behdasht'Ghadim, Havashenasi, and Mohitzist for 24 hours. Method of sampling and analysis were according to US Environmental Protection Agency (EPA) guideline. Raw data processing was done by Excel software and meteorological parameters were converted as input file into the Air Quality model (AQM). Finally, the rate of respiratory induced mortality and COPD attributed to sulfur and nitrogen dioxide in Ahvaz were calculated utilizing relative risk (RR) and baseline incidence (BI) related to health endpoints of sulfur and nitrogen dioxide in 2012. Descriptive statistics i.e. average and standard deviation was used for data analysis.

Results: Results showed that Naderi and Havashenasi stations had the highest and the lowest sulfur and nitrogen dioxide concentrations, respectively during 2012. Maximum annual concentrations of sulfur and nitrogen dioxide were $173 \mathrm{and} 58 \mu \mathrm{gg} / \mathrm{m}^{3}$, respectively, which observed during winter 2012. Approximately 5.6\% of the respiratory mortality and COPD cases happened when the sulfur and nitrogen dioxide concentrations were more than $20 \mu \mathrm{g} / \mathrm{m}^{3}$.

Conclusions: Air pollution resulting from motor vehicles and industrial emissions has drastically increased in Ahvaz. The lower level of RR value might be achieved if some control strategies for reducing sulfur and nitrogen dioxide emission were implemented.
\end{abstract}

Keywords: Sulfur Dioxide; Nitrogen Dioxide; Incidence; Hemoglobin Hb; Ahvaz

\section{Background}

Epidemiological studies have been asserted a consistent increased in the rate of morbidity and mortality due to the air pollution (1-4). Based on different studies, air pollutants have harmful effects on human health and hence they considered seriously by researchers, government, and people (5). The most important effects of air pollution include increasing the rates of hospital admissions, asthma attacks, cardiopulmonary diseases, death, and the number of the years of life lost (6-9). United States National Ambient Air Quality Standards (NAAQS) lists air pollutants as carbon monoxide, ozone, particulate matter, sulfur dioxide, nitrogen dioxide, and lead (10). Sulfur and nitrogen dioxide can be dangerous to the respiratory system and can also lead to irritation of eyes (11).
In the developing world, one of the common sources of air pollution is motor vehicles and industrial emissions. Long-term exposure to these irritants causes an inflammatory response in the lungs resulting in the narrowing of small airways and breakdown of lung tissue known as emphysema $(12,13)$. Several studies have demonstrated the association of short- and long-term effects of exposure to air pollutants with human health. Study results showed that chronic obstructive pulmonary disease affects 329 million people or nearly 5\% of the entire world population. In 2011, it ranked as the fourthleading cause of death, killing over 3 million people (14). Results showed that increase in hospital admissions for chronic obstructive pulmonary disease, cardiovascular disease, and respiratory mortality were attributed to

Copyright ( 2015 , Health Promotion Research Center. This is an open-access article distributed under the terms of the Creative Commons Attribution-NonCommercial 4.0 International License (http://creativecommons.org/licenses/by-nc/4.0/) which permits copy and redistribute the material just in noncommercial usages, provided the original work is properly cited. 
the increase in the sulfur and nitrogen dioxide concentration (15). Katsouyanni in a study in 12 European cities estimated that increase in daily mortality were $3 \%$ and $2 \%$, for an increase of $50 \mu \mathrm{g} / \mathrm{m}^{3}$ in concentrations of sulfur dioxide and particulates, respectively (16). In another study conducted in Taiwan, there was an association between nitrogen dioxide levels and hospital admission in patients suffered from ischemic stroke, COPD, and asthma exacerbation (17). Goudarzi et al. in their study estimated the number of myocardial infarction and cardiovascular death cases associated with sulfur dioxide exposure in Ahvaz, Iran during 2014 (18). Dockery et al. in a cohort study has shown the adverse health impact of long-term air pollution exposure in the 6US cities. This study demonstrated that chronic exposure to air pollutants was independently related to cardiovascular mortality (19). In a similar work by Mohammadi et al. they studied the association of daily mortality with sulfur and nitrogen dioxide levels in Ahvaz City in 2009 (20). In another study, Zallaghi et al. showed the effects of nitrogen dioxide in urban air on the health of citizens of west and southwest cities of Iran (21). Also Goudarzi et al. studied the association of daily mortality with sulfur and nitrogen dioxide levels in the Tehran in 2009 (22). Zallaghi et al. studied the association of daily mortality with sulfur and nitrogen dioxide levels in Ahvaz, Bushehr, and Kermanshah cities in 2010 (23).

Ahvaz has been long well-known for its industries as well as environmental pollution. In the last decade, another anthropogenic source of air pollution (dust storm) has been added to other environmental problems (24). Furthermore, health effects of air pollution in terms of sulfur dioxide, nitrogen dioxide, and particulate matter in most of the megacities, particularly Ahvaz were reported. Thus, we decided to assess health effects of sulfur and nitrogen dioxide, which has not studied yet (25-27). AirQ software was proved to be a valid and reliable tool to estimate the potential short-term effects of air pollution. It predicts health endpoints attributed to criteria pollutants, and allows the examination of various scenarios in which emission rates of pollutants are varied $(27,28)$.

\section{Objectives}

In such context, this study aimed to assess the respiratory mortality and COPD due to sulfur and nitrogen dioxide pollutant in the air of Ahvaz City (located in southwestern Iran) during 2012.

\section{Materials and Methods}

\subsection{Methods of the Study}

The present study is an ecological and model study. The information with regard to sulfur and nitrogen dioxide concentrations was taken from Ahvaz Department of Environment (ADoE). Sampling was performed in four stations for 24 hours. In this study, $70080(2 \times 24 \times 365 \times$ 4) air samples of sulfur and nitrogen dioxide were collected in Ahvaz during 2012. Raw air quality monitoring data were entered into an Excel spread sheet. These data were in volumetric base parts-per-million (PPM). Health effects are being related to the mass of pollutants inhaled and this is why the Air Quality model was on gravimetric basis $\left(\mu \mathrm{g} / \mathrm{m}^{3}\right)$. So, there was a conflict between $\mathrm{AQM}$ and ADoE data. Conversion between volumetric and gravimetric units (correction of temperature and pressure), coding, processing (averaging) and filtering were implemented for solving the problem. The station was considered as the highest when the mean value of this station is greater than the mean parameter at other stations and vice versa for the lowest. We calculated the relationship between $\mathrm{SO}_{2}$ and $\mathrm{NO}_{2}$ exposures and respiratory mortality and COPDcby $\mathrm{AirQ}_{2.2 .3}$ based on utilizing relative risk, attributable proportion, and baseline incidence from WHO data $(26,29)$. This model includes 4 screen inputs (supplier, AQ data, location, parameter) and two output screens (Figure 1$)(5,30)$. The primary and secondary standards of sulfur and nitrogen dioxide according to NAAQS is $150 \mu \mathrm{g} / \mathrm{m}^{3}$ and $100 \mu \mathrm{g} / \mathrm{m}^{3}$, respectively in 24 hours $(10,18,21)$.

\subsection{Geographical Features of Ahvaz}

Ahvaz, with a population of about 1 million, and an area of $8152 \mathrm{~km}^{2}$, is the capital of Khuzestan Province and located between longitudes $48^{\circ}$ and $49^{\circ} 29$ Eandlatitude $31^{\circ} 45 \mathrm{~N}(25,27,29)$. Data were taken from Ahvaz Department of Environment (ADoE). Stations were located "Naderi"at downtown, "Behdasht'Ghadim"at old school of public health,"Havashenasi” at bureau of meteorology,and "Mohitzist" head office of ADoE.

\subsection{Data Analysis}

For assessing of the health impacts of sulfur dioxide exposure in the ambient air of Ahvaz, we need population of city, coordination (latitude and longitude), number of stations and their data set. As it has mentioned, the most important part of the analysis is the data processing that encompasses removal or recovery of missing figures, correction of temperature and pressure on the basis of meteorological data, which requires shifting from volumetric to gravimetric units simultaneously, writing code, formulation, and filtering. In terms of epidemiological parameters, the relative risk, baseline incidence, and attributable proportion were calculated based on previous studies and also the following formulas. For instance, the attributable proportion was calculated from the following Equation:

$$
\mathrm{AP}=\frac{\operatorname{SUM}\{[\operatorname{RR}(c)-1] \times p(c)\}}{\operatorname{SUM}[\operatorname{RR}(\mathrm{c}) \times \mathrm{p}(\mathrm{c})}
$$



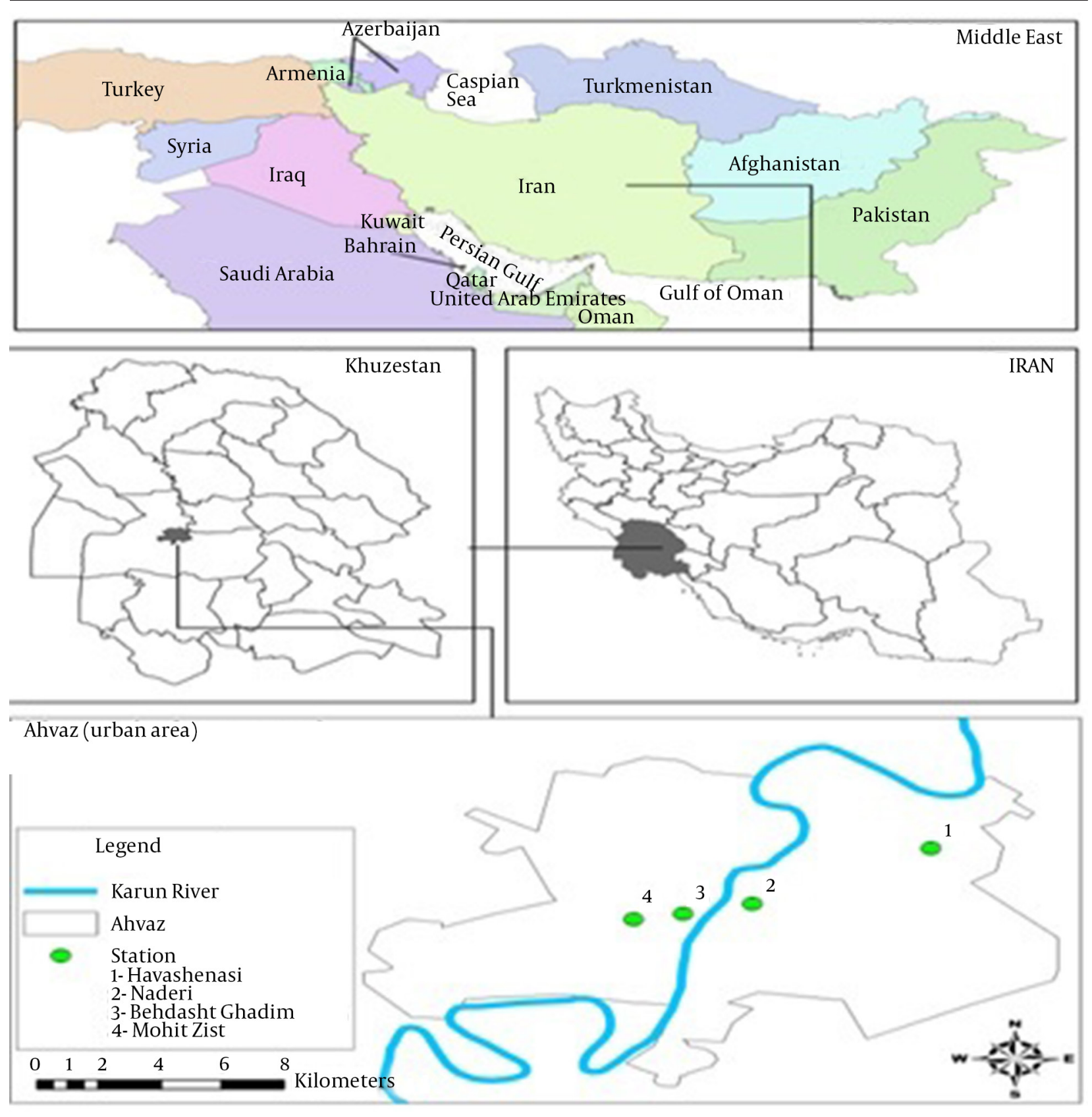

Figure 1. Location of the Study Area and Sampling Stations in the Khuzestan Province (Ahvaz City), in the South West of Iran

Where $\mathrm{p}$ is the proportion of the exposed population, and $\mathrm{RR}$ is the relative risk of disease (risk in exposed/risk to non-exposed or R1/Ro).

Relative risk (RR) is the risk of an event (or of developing a disease) relative to exposure. It is calculated by dividing the incidence rate among those exposed to the factor by the incidence rate to those not exposed to the factor $(31,32)$.

$$
\mathrm{PR}=\frac{\text { Incidenceintheexposed }}{\text { (Incidenceinthenon-exposed })}
$$

Attributable proportion was multiplied by baseline incidence and divided by 105 . Obtained value should be multiplied by the population (106). The results will be the excess cases of deaths and diseases associated with the given pollutants (sulfur and nitrogen dioxide).

\section{Results}

The annual average, summer average, winter average, and 98th percentile of sulfur and nitrogen dioxide concentrations in these stations were presented in Table 1. It 
shows that annual means of sulfur and nitrogen dioxide in Ahvaz were 160 and $37 \mu \mathrm{g} / \mathrm{m}^{3}$, respectively in 2012. Also it shows that the maximum concentrations of sulfur and nitrogen dioxide occurred in winter season.

Relative risk and estimated attributable proportion percentage for COPD and respiratory mortality were calculated in Table 2. Baseline incidence (BI) for these health endpoints due to nitrogen dioxide were 497 and 101.4/10 so the number of respiratory mortality and COPD were calculated at $32(\mathrm{RR}=1.01$ and $\mathrm{AP}=4.7651 \%)$ and $13(\mathrm{RR}=$ 1.0038 and $\mathrm{AP}=2.0721 \%)$ at centerline of relative risk. $\mathrm{BI}$ for these health endpoints due to sulfur dioxide were 101.4 and 66/105 so the number of COPD and respiratory mortality were calculated at $24(\mathrm{RR}=1.0044$ and $\mathrm{AP}=$ $3.1724 \%)$ and $21(\mathrm{RR}=1.014$ and $\mathrm{AP}=3.8350 \%)$ at centerline of relative risk.

The relation of COPD versus sulfur and nitrogen dioxide concentrations has been shown in Figure 2. Estimated cases attributed to sulfur and nitrogen dioxide related COPD at central of RR were 13 and 24, respectively. About $42 \%$ of these cases occurred in the days with concentrations lower than $80 \mu \mathrm{g} / \mathrm{m}^{3}$. Sixty-seven persons were estimated by the model as total cumulative number of COPD within one year of exposure.

Respiratory mortality versus sulfur and nitrogen dioxide concentration has been shown in Figure 3. About 51\% of this number occurred in the days with concentrations lower than $120 \mu \mathrm{g} / \mathrm{m}^{3}$. It should be noted that $82 \%$ of the above-mentioned numbers were matched with the days with the concentrations below $250 \mu \mathrm{g} / \mathrm{m}^{3}$.

\section{Discussion}

Because of the shortcomings in Iranian health registry system, it is impossible to use the health effects factors in this study. To solve this problem, as Ahvaz is a part of the Middle East, we used the data of the World Health Organization in the Middle East (RR and BI). The real estimation of the health effects exposure needs a long-term cohort study in the local community.

In this study, we estimated the respiratory mortality and COPD cases associated with short- and long-term fluctuations in the concentrations of sulfur and nitrogen dioxide, using AirQuality model in Ahvaz, Iran.
Table 1. Sulfur and Nitrogen Dioxide Concentrations $\left(\mu \mathrm{g} / \mathrm{m}^{3}\right)$ in Ahvaz, During 2012

\begin{tabular}{lcc}
\hline Time Period $^{\mathrm{a}}$ & $\begin{array}{c}\text { Nitrogen Dioxide } \\
(\mathbf{2 0 1 2})\end{array}$ & $\begin{array}{c}\text { Sulfur Dioxide } \\
(\mathbf{2 0 1 2})\end{array}$ \\
\hline Annual mean & $37 \pm 3.4$ & $160 \pm 18$ \\
\hline Spring mean & $17 \pm 1.9$ & $32 \pm 3.1$ \\
\hline Summer mean & $21 \pm 4.6$ & $46 \pm 4.9$ \\
\hline Autumn mean & $50 \pm 15.4$ & $120 \pm 24.3$ \\
Winter mean & $58 \pm 7.8$ & $173 \pm 18.7$ \\
$\begin{array}{l}\text { Annual 98th } \\
\text { percentile }\end{array}$ & 152 & 171 \\
\hline
\end{tabular}

${ }^{\mathrm{a}}$ Data concentrations mean is based on $\mu \mathrm{g} / \mathrm{m}^{3}$ and standard deviation for data add in column.

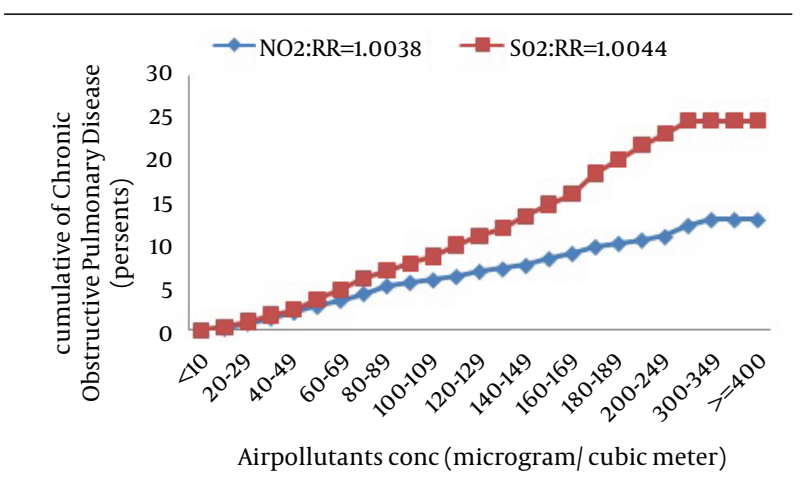

Figure 2. Relationship ofCumulative Numbers of Chronic Obstructive Pulmonary Disease With Sulfur and Nitrogen Dioxide Concentration

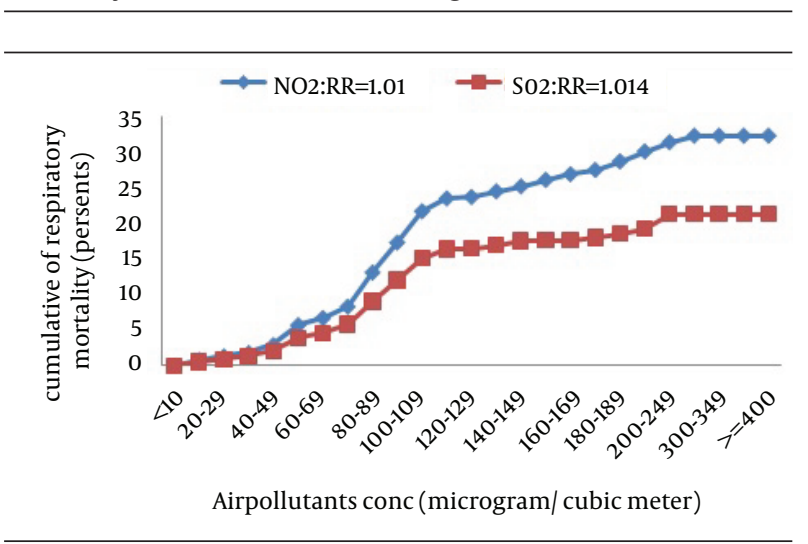

Figure 3. Relationship of Cumulative Numbers of Respiratory Mortality WithSulfur and Nitrogen Dioxide Concentration

Table 2. Relative Risks, Attributable Proportions and the Number of People Suffering From Respiratory Mortality and Chronic Obstructive Pulmonary Disease Due to Sulfur and Nitrogen Dioxide

\begin{tabular}{lccc}
\hline Health effects attributable to pollutant & $\mathbf{R R}$ (Medium) & $\mathbf{A P}, \%$ & Estimated Number of Excess Cases (Persons) \\
\hline Respiratory mortality $\left(\right.$ due to $\mathrm{NO}_{\mathbf{2}}$ ) & 1.01 & 4.7651 & 32 \\
Respiratory mortality $\left(\right.$ due to $\mathrm{SO}_{\mathbf{2}}$ ) & 1.014 & 3.8350 & 21 \\
Chronic obstructive pulmonary disease $\left(\mathbf{d u e}\right.$ to $\left.\mathrm{NO}_{\mathbf{2}}\right)$ & 1.0038 & 2.0721 & 13 \\
Chronic obstructive pulmonary disease $\left(\mathrm{SO}_{\mathbf{2}}\right)$ & 1.0044 & 3.1724 & 24 \\
\hline
\end{tabular}


Results showed that Ahvaz with approximately 5.6\% incidence respiratory mortality and COPD cases is one of the most polluted cities. The higher percentage of these mortality and morbidity perhaps could be due to the higher average sulfur and nitrogen dioxide or because of emissions from heavy industrial and motor vehicles in Ahvaz. Table 1 shows that winter and spring had the highest and the lowest 24-hour average of pollutants concentrations during this year, respectively. Relative risk, the percentage, attributable ratio and the cardiovascular death, respiratory mortality and COPD attributed to the sulfur and nitrogen dioxide is estimated in Table 2. Figures 2 and 3 have illustrated sulfur and nitrogen dioxide concentrations versus related health endpoints and average concentrations during Specify these years. Based on the results of this study, 8.6\% and 10\% of all respiratory mortality and COPD were attributed to respiratory concentrations over $30 \mu \mathrm{g} / \mathrm{m}^{3}$.

By reviewing the long-term national database, researchers found a higher risk of death from respiratory diseases associated with increases in sulfur and nitrogen dioxide concentrations. According to one study in 6 Italian cities, it was shown that with an increase in the sulfur dioxide pollutant levels of $10 \mu \mathrm{g} / \mathrm{m}^{3}$ of daily average was associated with an increase of $2.8 \%$ in cardiovascular diseases (33). In 2010, Zallaghi et al. studied health effects of air pollution in Ahvaz, Bushehr, and Kermanshah. Based on their results, approximately 3.5\% in Ahvaz, 2.1\% in Kermanshah, and $1.1 \%$ of COPD cases were attributed to nitrogen dioxide (23). High percentage of the observed health endpoints in this study was associated with high concentration of measured ozone and existing heavy industry such as oil, petrochemical, and steel in Ahvaz. Study of Ballester et al. in Valencia, Spain showed that an increase in the sulfur dioxide levels of $10 \mu \mathrm{g} / \mathrm{m}^{3}$ of daily average was associated with an increase of $3 \%$ in all circulatory diseases (34). In the United States, approximately $6.3 \%$ of the adult population(15 million people) diagnosed with COPD have been attributed to nitrogen dioxide (35). Results of this study are different from other studies because of the geographic, demographic, and climate characteristics. In a similar work, Gudarzi et al. estimated the sulfur dioxide hygienic effects in Tehran (capital of Iran) in 2009. Based on their results, almost $7.82 \%$ and 3.6\% of all cases of whole deaths and hospital admissions due to respiratory diseases are attributed to sulfur dioxide (22). Also, Mohamadi et al. study showed that approximately $3 \%$ of hospital admission for COPD occurred when the nitrogen dioxide concentration was over $20 \mu \mathrm{g} / \mathrm{m}^{3}(20)$. Based on the results of our study, the number of cases of the health effects was relatively higher because of the greater pollutant concentration in Ahvaz. In 2010, Zalaghi et al. surveyed health effects of air pollution in Ahvaz, Bushehr, and Kermanshah. Based on their results, approximately 4.4\% in Ahvaz, $8.64 \%$ in Kermanshah, and 3.33\% of total respiratory deaths were attributed to sulfur dioxide (23). The results of this study showed that the concentration of ozone in Ahvaz is very high compared to Kermanshah and Bushehr. Based on the results of our study, the number of cases of health effects was the relatively higher because of greater concentration in Ahvaz city. Lipmann et al. studied the health effects of air pollution in Detroit, USA. Their results showed that an increase in the pollutant sulfur dioxide level of $10 \mu \mathrm{g} / \mathrm{m}^{3}$ of daily average was associated with an increase of $2 \%$ in hospital admissions (36). In 2014, Goudarzi et al. estimated the number of myocardial infarction and cardiovascular death cases associated with sulfur dioxide exposure in Ahvaz, Iran. Based on their results, total number of myocardial infarction and cardiovascular deaths attributed to sulfur dioxide were respectively 37 and 165 (18). Zallaghi et al. estimated nitrogen dioxide health endpoint in urban air on the health status of west and southwest cities, Iran; almost $7.5 \%$ and $5.6 \%$ of all cardiovascular death and myocardial infarction cases were attributed to sulfur dioxide (23). Nonetheless, concentration of sulfur dioxide in Ahvaz was much higher compared to Tehran. In another study, Zallaghi et al. showed the effects of nitrogen dioxide in urban air on the health status of west and southwest cities of Iran (21).

There are many confounding factors such as socioeconomic status and demographic variables affecting the incidence and prevalence of health effects of air pollutants. In this study, we used a standard model that eliminated the confounding factors based on the default. Although the results of this study are in line with results of other researches around the world, as the geographic, demographic, and climate characteristics are different, there is still need for further studies to specify local RR and BI. The high percentage of observed health endpoints was associated with high concentration of measured sulfur and nitrogen dioxide. Unfortunately, the major limitations of this study were the lack of databases and indicators, which forced us to use the figures of WHO (Middle East Region) for calculating health effects attributed to sulfur and nitrogen dioxide. Also careful monitoring of sulfur and nitrogen dioxide, public education, control and optimization of urban traffic, application of technical methods for decreasing sulfur and nitrogen dioxide from sources such as oil and petrochemical industry and regulations of urban development will have an important role in controlling air pollutants, including sulfur and nitrogen dioxide.

\section{Acknowledgements}

The authors would like to thank Ahvaz Jundishapur University of Medical Sciences for their financial support of this research.

\section{Authors' Contributions}

Study concept, design, and critical revision of the manuscript for important intellectual content: Sahar Geravandi, Gholamreza Goudarzi, Sepideh Sadat Taghavirad, 
Shokrollah Salmanzadeh and Mohammad Javad Mohammadi; Drafting of the manuscript and advisor, conducting experiments: Mohammad Javad Mohammadi.

\section{Funding/Support}

This study was supported by Ahvaz Jundishapur University of Medical Sciences.

\section{References}

1. Pope CA, 3rd, Dockery DW. Health effects of fine particulate air pollution: lines that connect. I Air Waste Manag Assoc. 2006;56(6):709-42.

2. Mirhosseini SH, Zare MR, Birjandi M, Fatehizadeh A. Analysis of Particulate matter (PM10and PM2.5) concentration in Khorramabad city. International Journal of Environmental Health Engineering. 2013;2(1):3.

3. Scapellato ML, Lotti M. Short-term effects of particulate matter: an inflammatory mechanism? Crit Rev Toxicol. 2007;37(6):461-87.

4. Baccarelli A, Barretta F, Dou C, Zhang X, McCracken JP, Diaz A, et al. Effects of particulate air pollution on blood pressure in a highly exposed population in Beijing, China: a repeated-measure study. Environ Health. 2011:10:108.

5. Goudarzi G, Mohammadi MJ, Angali K, Mohammadi B, Soleimani Z, Babaei A, et al. Estimation of Number of Cardiovascular Death, Myocardial Infarction and Chronic Obstructive Pulmonary Disease (COPD) from NO2 Exposure using Air Q Model in Ahvaz City During 2009. Iranian J Health and Environment. 2013;6(1):91-102.

6. Kelly FJ. Oxidative stress: its role in air pollution and adverse health effects. Occup Environ Med. 2003:60(8):612-6.

7. Goudarzi G, Zallaghi E, Saki A, Neisi AK, Ahmadi Angali K, Mohammadi MJ. Cardiopulmonary Mortalities and Chronic Obstructive Pulmonary Disease Attributed to Ozone Air Pollution.J Archive of Hygiene Sci. 2013;2(2):62-7.

8. Ritz B, Yu F, Fruin S, Chapa G, Shaw GM, Harris JA. Ambient air pollution and risk of birth defects in Southern California. Am J Epidemiol. 2002;155(1):17-25.

9. Clancy L, Goodman P, Sinclair H, Dockery DW. Effect of air-pollution control on death rates in Dublin, Ireland: an intervention study. Lancet. 2002;360(9341):1210-4.

10. US Environmental Protection Agency . National Ambient Air Qual ity Standards (NAAQS): for air pollutant. US Environmental Protection Agency editor.; 2014.

11. Rahila R, Siddiqui M. Review on effects of Particulates; Sulfur Dioxide and Nitrogen Dioxide on Human Health. International Res Environ Sci. 2014;3(4):70-3.

12. Fishman AP. One hundred years of chronic obstructive pulmonary disease. Am J Respir Crit Care Med. 2005;171(9):941-8.

13. Rabe KF, Hurd S, Anzueto A, Barnes PJ, Buist SA, Calverley P, et al. Global strategy for the diagnosis, management, and prevention of chronic obstructive pulmonary disease: GOLD executive summary. Am J Respir Crit Care Med. 2007;176(6):532-55.

14. WHO . The 10 leading causes of death in the world 2000 and 2011 Organization WH editor.; 2013.

15. Barnett AG, Williams GM, Schwartz J, Best TL, Neller AH, Petroeschevsky AL, et al. The effects of air pollution on hospitalizations for cardiovascular disease in elderly people in Australian and New Zealand cities. Environ Health Perspect. 2006;114(7):1018-23.

16. Katsouyanni K, Touloumi G, Spix C, Schwartz J, Balducci F, Medina S, et al. Short-term effects of ambient sulphur dioxide and particulate matter on mortality in 12 European cities: results from time series data from the APHEA project. Air Pollution and Health: a European Approach. BMJ. 1997;314(7095):1658-63.

17. Tsai SS, Goggins WB, Chiu HF, Yang CY. Evidence for an associa- tion between air pollution and daily stroke admissions in Kaohsiung, Taiwan. Stroke. 2003;34(11):2612-6.

18. Goudarzi G, Geravandi S, Salmanzadeh S, Mohammadi MJ, Zallaghi E. The Number of Myocardial Infarction and Cardiovascular Death Cases Associated with Sulfur Dioxide Exposure in Ahvaz, Iran. I Archives of Hygiene Sci. 2014;3(3):112-9.

19. Dockery DW, Pope C3, Xu X, Spengler JD, Ware JH, Fay ME, et al. An association between air pollution and mortality in six U.S. cities. N Engl J Med.1993;329(24):1753-9.

20. Mohammadi MJ. . Studied hygienic effects of air pollution in town Ahvaz in 2009 with model Air Q. National Conference of the Air Pollution. 2009.

21. Zallaghi E, Goudarzi G, Nourzadeh H. M. , Moosavian SM, Mohammadi MJ. Assessing the Effects of Nitrogen Dioxide in Urban Air on Health of West and Southwest Cities of Iran. Jundishapur Journal of Health Sciences. 2014;6(4).

22. Goudarzi G. . Quantification of health effects of air pollution in Tehran and determining the impact of a comprehensive program to reduce air pollution in Tehran on the third axis. National Conference of the Air Pollution. 2007.

23. Zallaghi E. . Survey of health Effects of Air Pollution Ahvaz, Bushehr and Kermanshah with Use of AIRQ Model. 2010.

24. Soleimani Z, Goudarzi G, Naddafi K, Sadeghinejad B, Latifi SM, Parhizgari N, et al. Determination of culturable indoor airborne fungi during normal and dust event days in Ahvaz, Iran. Aerobiologia. 2012;29(2):279-90.

25. Goudarzi G, Shirmardi M, Khodarahmi F, Hashemi-Shahraki A Alavi N, Ankali KA, et al. Particulate matter and bacteria characteristics of the Middle East Dust (MED) storms over Ahvaz, Iran. Aerobiologia. 2014;30(4):345-56.

26. Geravandi S, Mohammadi MJ , Goudarzi G, Ahmadi Angali K, Neisi AK, Zalaghi E. Health effects of exposure to particulate mat ter less than 10 microns (PM10) in Ahvaz.JQUMS. 2014;18(5):28-36.

27. Zallaghi E, Goudarzi G, Geravandi S, Mohammadi MJ, Vosoughi Niri M, Vesyi E. Estimating the prevalence of cardiovascular and respiratory diseases due to particulate air pollutants in Tabriz air. Ilam Uni Med Sci. 2014;22(1):84-91.

28. sadat Taghavirad S, Davar H, Mohammadi MJ. The a study on concentration of BETX vapors during winter in the department of ports and shipping located in one of the southern cities of Iran. International J Current Life Sci. 2014;4(9):5416-20.

29. Goudarzi G, Geravandi S, Naimabadi A, Mohammadi MJ, Neisi AK, sadat Taghavirad S. Cardiovascular deaths related to Carbon monoxide Exposure in Ahvaz, Iran. Iranian Journal of Health, Safety Environment. 2014;1(3):126-31.

30. Goudarzi G, Mohammadi MJ, Angali KA, Neisi AK, Babaei AA, Mohammadi B, et al. Estimation of Health Effects Attributed to NO2 Exposure Using AirQ Model. Archives of Hygiene Sci. 2012;1(1):59-66.

31. Zallaghi E, Goudarzi G, Geravandi S, Mohammadi MJ. Epidemiological Indexes Attributed to Particulates With Less Than $10 \mathrm{Mi}$ crometers in the Air of Ahvaz City During 2010 to 2013. Health Scope. 2014:3(4).

32. Rockhill B, Newman B, Weinberg C. Use and misuse of population attributable fractions. Am J Public Health. 1998;88(1):15-9.

33. Biggeri A, Bellini P, Terracini B, Italian MG. [Meta-analysis of the Italian studies on short-term effects of air pollution]. Epidemio Prev. 2001;25(2 Suppl):1-71.

34. Ballester F, Tenias JM, Perez-Hoyos S. Air pollution and emergency hospital admissions for cardiovascular diseases in Valencia, Spain.J Epidemiol Community Health. 2001;55(1):57-65.

35. Centers for Disease C, Prevention.. Chronic obstructive pulmonary disease among adults--United States, 2011. MMWR Morb Mortal Wkly Rep. 2012;61(46):938-43.

36. Lippmann M, Ito K, Nadas A, Burnett RT. Association of particulate matter components with daily mortality and morbidity in urban populations. Res Rep Health Eff Inst. 2000(95):5-72. 